\title{
Introduction of Network-Based Healthcare at Kaiser Permanente
}

\author{
Lonneke Rompen ${ }^{\mathrm{a}, *}$, Nienke M. de Vries ${ }^{\mathrm{a}}$, Marten Munneke ${ }^{\mathrm{a}}$, Carolyn Neff ${ }^{\mathrm{b}}$, Todd Sachs ${ }^{\mathrm{b}}$, \\ Steve Cedrone ${ }^{\mathrm{b}}$, Jason Cheves ${ }^{\mathrm{b}}$ and Bastiaan R. Bloem ${ }^{\mathrm{a}}$ \\ ${ }^{a}$ Radboud University Medical Centre, Donders Institute for Brain, Cognition and Behaviour, \\ Department of Neurology, Nijmegen, The Netherlands \\ ${ }^{\mathrm{b}}$ Kaiser Permanente, Southern California Permanente Medical Group, CA, USA
}

\begin{abstract}
.
Background: Early 2014, Kaiser Permanente decided to adopt an innovative model for network-based allied healthcare for persons with Parkinson's disease (PD), based on the principles of the Dutch ParkinsonNet.

Objective: We present the interventions that were performed to implement this method at Kaiser Permanente and we show the first outcomes based on these interventions.

Methods: In this study, 57 physical therapists, 18 speech therapists and 20 occupational therapists, as well as 13 medical centers across the state of California were included. Nine interventions were performed more or less simultaneously, including training and education of healthcare providers and patients, a train the trainer curriculum, organizing IT, streamlining referral processes and building networks.

Results: At the start, less than $30 \%$ of the patients within the Southern California Region received specialized allied health treatment (consisting of, i.e., gait training, voice training or guidance in activities of daily life). After one year, almost $55 \%$ of patients received specialized allied health treatment. In the second year, this number increased to just under $67 \%$, suggesting a sustained concentration of care (the second core component of networked care). This can be seen as a first indicator for successful implementation of the ParkinsonNet network at Kaiser Permanente.

Conclusions: The importance of these findings lies in the fact that a healthcare innovation that proved effective in one country can be transferred successfully to another country and to another healthcare system.
\end{abstract}

Keywords: Networks, integrated care, health reform, Parkinson's disease, ParkinsonNet, Kaiser Permanente

\section{INTRODUCTION}

In early 2014, Kaiser Permanente decided to adopt an innovative model for network-based allied healthcare for persons with Parkinson's disease (PD), based on the principles of the Dutch ParkinsonNet. ParkinsonNet is grounded upon three pillars:

\footnotetext{
${ }^{*}$ Correspondence to: Lonneke Rompen, MSc, MBA, Radboud University Medical Centre, Department of Neurology, P.O. Box 9101, 6500 HB, Nijmegen, The Netherlands. Tel.: +31 243614701; E-mail: lonneke.rompen@radboudumc.nl.
}

patient empowerment (through education); professional empowerment (through dedicated training programs); and team empowerment (by organizing care in regional multidisciplinary networks) [1-3]. Improved levels of professional expertise and skills training are achieved through professional training based on evidence-based guidelines [4-6], in particular for allied health professionals (e.g., care professionals trained to provide services in healthcare other than a physician or a registered nurse, such as physical therapists, occupational 
therapists, speech and language therapists and nutritionists). After completing the professional expertise and skills training, providers are identified as PD experts and become part of the regional ParkinsonNet. Another key component is concentration of care among these expert professionals, because seeing a large number of patients helps to gain cumulatively more experience and to deliver optimal quality of care [7]. Furthermore, the experts work together to facilitate an optimal treatment plan for PD patients. Patients themselves become more knowledgeable through coaching and education programs, which are designed by teams of expert professionals. Taken together, this multifaceted approach has been shown to significantly improve the quality of care in the Netherlands, reduce disease complications among patients with PD and save costs $[1,2,8]$. The cost savings were modest but significant, achieved through greater efficiency of care, a reduction of disease complications (e.g., fewer hospital admissions for fractures), and emphasis on patient self-management (which reduces the dependency on medical care). The overall cost savings in the Netherlands equal around 5\% of the annual expenditure on chronic Parkinson care. Implementation of the Dutch ParkinsonNet model in California was therefore expected to contribute to the triple-aim: better care, better health and lower costs [9].

However, translating a healthcare innovation into another (cultural) setting may require structural adaptations to the innovation and a variety of implementation strategies [10-12]. Here, we will present our experience with the first phase of the implementation of PD network care in California, specifically focusing on the achieved concentration of care among expert allied health professionals, who were trained as part of the Dutch network approach and their training programs.

\section{METHODS}

The ParkinsonNet model was specifically developed to improve care for patients with PD in the Netherlands. Because of differences between countries in, for example, organization of care, the model could not be "copy pasted" into the Kaiser Permanente system. Although the basic principles of an integrated care model are universal, some adaptations to the model had to be made to match the specific situation in California. First, the Dutch net- work is a community-based network with regions centered around large hospitals. Most trained professionals work within the community and treat patients in their own (private) practice. Within Kaiser Permanente, on the other hand, the networks had to be hospital-based, because hardly any care is provided within the community. Because of this, patients need to travel to the clinic to receive PD care, which might impose a barrier for some patients to be seen by an expert provider. Second, all professionals within the Californian network are employed by Kaiser Permanente. Therefore, system changes to make the network more efficient and effective can be done through hierarchical decisions, instead of consensus among professionals as used the Dutch ParkinsonNet. This was expected to increase the pace of implementation of this new model in daily clinical practice.

\section{Interventions}

In building an allied healthcare network within Kaiser Permanente, nine interventions were performed more or less simultaneously (Table 1). This included training 57 physical therapists, 18 speech therapists and 20 occupational therapists in medical centers across Southern California. These therapists were trained over the course of three days based on an evidence-based treatment guideline (e.g., the European Physiotherapy Guideline for Parkinson's Disease (2010)) in order to increase their level of knowledge and expertise.

At the same time, a project team was installed to build the area networks. The project team was responsible for organizing the training, facilitating collaboration, sharing knowledge, and implementing supporting IT systems. The project team consisted of one consultant from the Netherlands who guided the implementation, a project lead, and a trainer from each of the three professional disciplines. These trainers received a train-the-trainer curriculum in order to become the local area experts, to further enhance local implementation and to ascertain a sustained functioning of the network. Even though the ParkinsonNet network is primarily an allied health network, neurologists were also involved by informing them about the importance of non-medical treatments, streamlining the referral process and facilitating easy and efficient communication and collaboration between the different professionals. Supporting IT systems included: (1) a website for patients with reliable and relevant information about PD; (2) a 'healthcare finder', 
Table 1

Interventions for implementing networked care for allied health professionals, as originally developed for the Dutch ParkinsonNet

\begin{tabular}{|c|c|}
\hline Intervention & Description \\
\hline $\begin{array}{l}\text { Professional training of } \\
\text { providers }\end{array}$ & $\begin{array}{l}\text { The first intervention was to train allied health professionals in order to develop PD-specific expertise. } \\
\text { These trainings were based upon evidence-based guidelines [13-15] modified slightly changed to fit } \\
\text { the specific system at Kaiser Permanente. }\end{array}$ \\
\hline $\begin{array}{l}\text { Facilitate creation of } \\
\text { networks }\end{array}$ & $\begin{array}{l}\text { The trained providers should work together in networks. Therefore, an additional objective was to train } \\
\text { and encourage providers to function as multidisciplinary patient-centered teams by organizing network } \\
\text { meetings during which collaboration was discussed. }\end{array}$ \\
\hline Co-designing care plans & $\begin{array}{l}\text { A third and invaluable step was working closely with patients using video ethnography to organize } \\
\text { pathways such that patients receive care how, when, and where they want it [15]. }\end{array}$ \\
\hline Organize IT & $\begin{array}{l}\text { Digital networking tools were created and installed to connect providers, enabling quicker patient } \\
\text { diagnoses and referrals and facilitating the exchange of best practices and clinical insights. For } \\
\text { example, a digital platform was developed which allowed providers to easily access moderated } \\
\text { information on PD, ask and answer PD-related questions, and discuss different topics regarding PD. }\end{array}$ \\
\hline Train-the-trainers & $\begin{array}{l}\text { To build a sustainable network, local staff were trained on the principles of the Dutch ParkinsonNet. A } \\
\text { train-the-trainer curriculum was utilized in order to build specific expertise in PD, but also to gain } \\
\text { expertise in other important areas, such as didactic skills training. Developing such local expertise } \\
\text { ensured that the ParkinsonNet model was self-sustaining within Kaiser Permanente after the } \\
\text { implementation period. }\end{array}$ \\
\hline Inform involved providers & $\begin{array}{l}\text { Raising awareness in a way that all involved providers knew about the existence of ParkinsonNet and } \\
\text { could act according to the current network guidelines. This included the involvement of neurologists. }\end{array}$ \\
\hline $\begin{array}{l}\text { Streamline referrals and } \\
\text { concentration of care }\end{array}$ & $\begin{array}{l}\text { According to the Dutch model, all patients should ideally be treated by experts in PD. Therefore, referrals } \\
\text { should be streamlined to make sure that trained professionals can treat as many PD patients as possible. } \\
\text { Specific interventions included facilitating quick referrals from primary care providers to neurologists } \\
\text { by providing a red-flag sheet to help clarify definitive referral criteria. In addition, changes were made } \\
\text { to the Kaiser Permanente electronic medical record so that generically trained neurologists (a total of } \\
108 \text { general neurologists in the Southern California Region) were alerted by the system when a } \\
\text { patient's condition warranted a referral to a PD specialist (a total of } 9 \text { movement disorder specialists in } \\
\text { the Southern California Region). Finally, efforts were made to promote the importance of allied health } \\
\text { care to the referring physicians, and to stress the importance of a timely referral. }\end{array}$ \\
\hline Educate patients & $\begin{array}{l}\text { Another intervention was to educate patients about the existence of ParkinsonNet, and also to teach } \\
\text { patients how to better manage their lives. Throughout the region, education classes were organized and } \\
\text { a smart IT tool that connected patients and providers online was implemented in order to educate } \\
\text { patients. This tool, consisting of an online community platform for providers and patients allowed } \\
\text { patients and their families to ask specific questions that could be answered by trained providers. } \\
\text { Moreover, PD related knowledge and information was shared on this platform and was made easily } \\
\text { accessible for all members to create a PD knowledge base for both patients, family members and } \\
\text { providers. This patient education is a powerful way of enhancing self-management by people with PD. }\end{array}$ \\
\hline $\begin{array}{l}\text { Build a network for } \\
\text { movement disorder } \\
\text { specialists }\end{array}$ & $\begin{array}{l}\text { The final intervention was to build a network for movement disorder specialists in which they could share } \\
\text { knowledge and information, discuss cases and create documents that could help other providers such } \\
\text { as general neurologists to refer patients in a timely manner. For this, a red-flag document was created } \\
\text { to explain why and when a patient should be referred to a movement disorder specialist or to an allied } \\
\text { healthcare provider. This helped in raising awareness about both the disease and the newly built } \\
\text { network, and in making sure that patients receive a correct and timely referral. Moreover, all medical } \\
\text { centers involved their neurologists in the regional ParkinsonNet to facilitate easy communication and } \\
\text { collaboration between all the professionals working in the network. }\end{array}$ \\
\hline
\end{tabular}

where patients as well as referring physicians can find the expert professionals, and (3) an online community platform for healthcare providers, patients and family members. The platform is used for questions (patients) and answers (expert professionals) and to share knowledge and information.

\section{Data collection}

The objective here was to report on the concentration of care among the expert professionals as a first indicator of the success of implementation of ParkinsonNet (using ICD9 and ICD10 PD diagnosis codes). For all identified $\mathrm{PD}$ patients, the electronic medical health records were extracted from Health Connect the electronic health system that Kaiser Permanente is using - to collect several variables including visit type, provider type and name, contact date, diagnosis date and specialty/department name.

Subsequently, we calculated the number of patients that were treated at least once by an expert professional. The data were collected starting from January 
2015 and have since then been updated monthly (last check included in this paper May 2018).

\section{RESULTS}

Approximately 14,000 PD patients were treated by Kaiser Permanente in 2015 . The overall average age of these patients was 72.19 with $40.3 \%$ female and $59.7 \%$ male. In 2015, the specialized allied health network within Kaiser Permanente has reached full coverage in the state of California, meaning that all medical centers employ at least one expert professional in each of the three trained disciplines: physical therapy, occupational therapy and speech language therapy. Before the start of the network, only $29 \%$ of the PD patients in the Southern California Region received specialized allied health treatment. During the first year of implementation, almost $55 \%$ of the PD patients was treated by an expert physical- occupational or speech and language therapy provider within Kaiser Permanente's Southern California Region. In the second year, this number increased to just under $67 \%$, which led to a total increase of $38 \%$. See Fig. 1.

\section{DISCUSSION}

Concentration of care is only an initial-but important-indicator of a successful implementation of specialized networked care within the Kaiser Permanente system. Two years after the first training program was launched, around $67 \%$ of the PD patients were treated by an expert allied health professional. Interestingly, it took almost 10 years to achieve the same level of concentration of care within the Dutch ParkinsonNet. This more rapid process is likely due to the fact that all providers in California belonged to one healthcare organization that internally promoted the concept. In the present analysis, we did not examine health benefits to patients, as we expect that it will take more time to see effects on, e.g., hip fractures or quality of life. Indeed, freshly trained networks in the Netherlands were not associated with health benefits for patients [13], whereas more mature networks - where professionals have accumulated expertise by treating a large number of patients - did translate into tangible benefits to patients $[1,8]$. Several studies have shown that a network approach for PD patients leads to better quality of care, fewer disease complications and marked cost savings in the Netherlands [8, 13, 14]. As the Kaiser Permanente

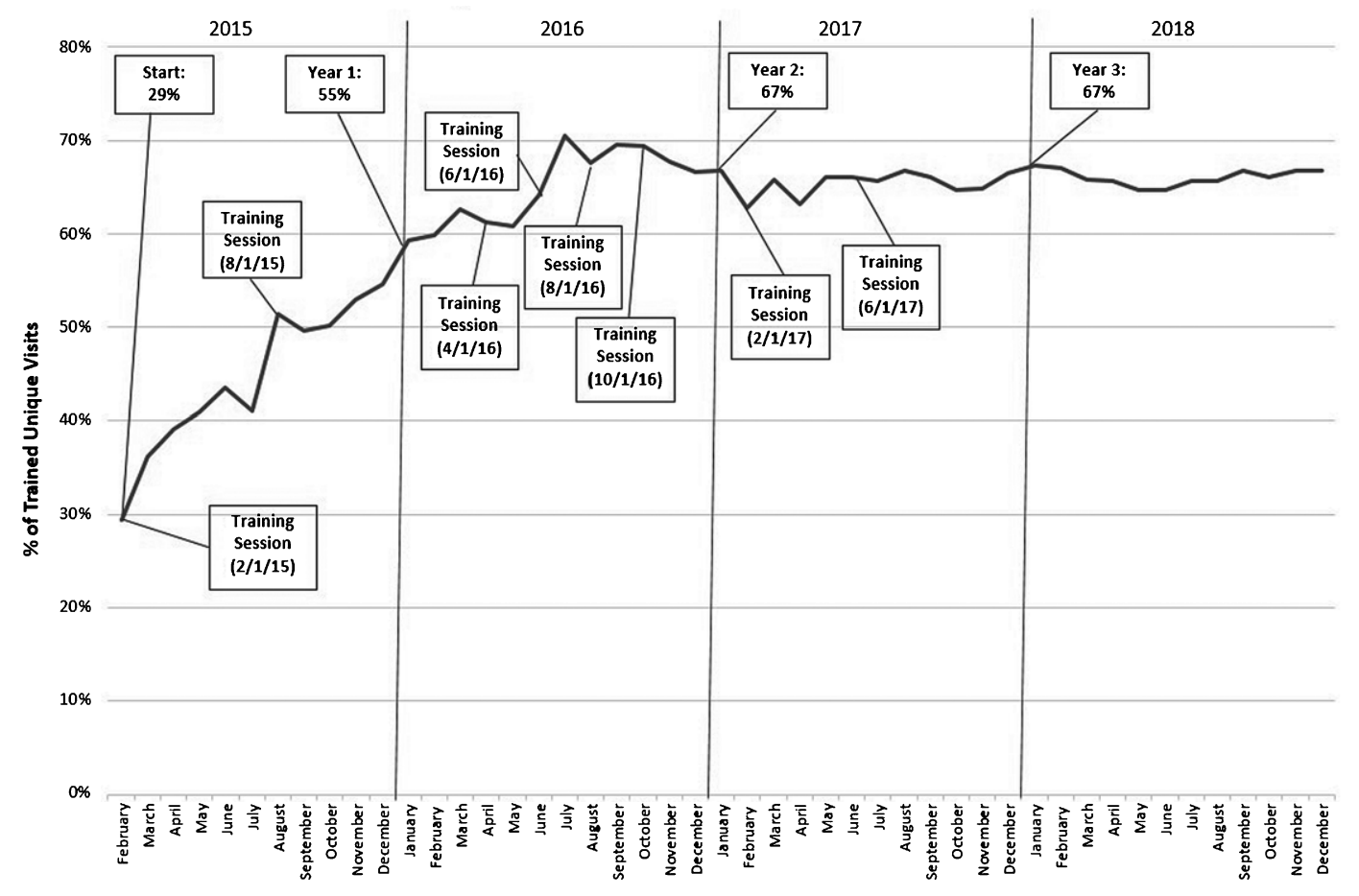

Fig. 1. Percentage of unique visits to a ParkinsonNet professional. 
network continues to grow and mature, future analyses will have to focus on evaluating outcomes such as hospital admission, hip-fracture rates and healthcare costs.

Kaiser Permanente integrated components of the Dutch ParkinsonNet program into their existing care model for PD patients. Through professional training of providers, patient education, the creation of networks and specifically designed care plans, the concentration of allied healthcare increased. After these initial results, ParkinsonNet is now also being implemented in Northern California. Top-down promotion of the concept by a single healthcare system will help facilitate a rapid introduction. Other determinants that may help with the sustained introduction of network care from one country to another country include the sharing of key knowledge (train-thetrainer concept), a controlled start in pilot regions before scaling, involving patients involved from the outset, and making modifications to adjust the approach to the existing services within the Kaiser Permanente system. Meanwhile, other disease populations are now beginning to benefit from the lessons learned from the networked care approach, as new networks are now being built for patients with other chronic conditions who are likely to benefit from the generic components of professional training, patient education and interdisciplinary collaboration.

\section{Strength and limitations of this study}

- For this study, only a limited data set was available for analysis.

- The outcomes of this study are only one first indicator of the success of implementation of networked care within Kaiser Permanente. Long term results will be shown after a longer implementation period.

- This study shows the potential of replicating a method that was developed in another country and in another health care system.

- The method in this study is based on a substantial amount of scientific research and evidence and on prior implementation trajectories.

\section{ACKNOWLEDGMENTS}

Prof. Bastiaan R. Bloem was supported by a research grant of the National Parkinson Foundation and The Netherlands Organization for Health, Research and Development. Dr. N.M. de Vries was supported by a research grant of The Netherlands
Organisation for Health, Research and Development. The authors thank Rodney Cooley, Helene Martel, Elizabeth Suden, Jann Dorman, Heidi Bremner, Chris DiStasio, Nancy Adachi, and Martin Yuson for their contribution to the implementation of ParkinsonNet at Kaiser Permanente.

This research received no specific grant from any funding agency in the public, commercial or not-forprofit sectors.

\section{CONFLICT OF INTEREST}

We declare the following interests: LR, CN, TS, SC and JC were employed at Kaiser Permanente at the time of the study. Dr. De Vries reports a research grant of the Netherlands Organization for Health Research and Development. Dr. Munneke is managing director of ParkinsonNet. BRB currently serves as associate editor for the Journal of Parkinson's Disease, serves on the editorial board of Practical Neurology, has received honorariums from serving on the scientific advisory board for Zambon, Abbvie, Biogen, and $\mathrm{UCB}$, has received fees for speaking at conferences from AbbVie, Zambon, and Bial, and has received research support from the Netherlands Organisation for Scientific Research, the Michael J Fox Foundation, UCB, Abbvie, the Stichting Parkinson Fonds, the Hersenstichting Nederland, the Parkinson's Foundation, Verily Life Sciences, Horizon 2020, the Topsector Life Sciences and Health, and the Parkinson Vereniging.

\section{Data sharing statement}

The data used for this study are the sole property of Kaiser Permanente and cannot be shared.

\section{REFERENCES}

[1] Bloem BR, Munneke M (2014) Revolutionising management of chronic disease: The ParkinsonNet approach. BMJ 348, g1838.

[2] Bloem BR, Rompen L, Vries NM, Klink A, Munneke M, Jeurissen P (2017) ParkinsonNet: A low-cost health care innovation with a systems approach from the Netherlands. Health Aff (Millwood) 36, 1987-1996.

[3] Gray BH, Sarnak DO, Tanke M (2016) ParkinsonNet: An Innovative Dutch Approach to Patient-Centered Care for a Degenerative Disease. The Commonwealth Fund.

[4] Keus S, Munneke M, Graziano M, Paltamaa J, Pelsoin E, Domingos J, Bruhlmann S, Ramaswamy B, Prins J, Struiksma C, Rochester L, Nieuwboer A, Bloem B (2014) European Physiotherapy Guideline for Parkinson's Disease, KNGF/ParkinsonNet, The Netherlands. 
[5] Kalf H, de Swart B, Bonnier-Baars M, Kanters J, Hofman M, Kocken J, Miltenburg M, Bloem B, Monneke M (2008) Guidelines for Speech-Language therapy in Parkinson's Disease, ParkinsonNet/NPF, Nijmegen, The Netherlands.

[6] Sturkenboom I, Thijssen M, Gons-van Elsacker J, Jansen I, Maasdam A, Schulten M, Vijver-Visser D, Steultjens E, Bloem B, Munneke M (2008) Guideline for Occupational Therapy in Parkinson's Disease, ParkinsonNet/NPF, Nijmegen, The Netherlands.

[7] Nijkrake MJ, Keus SH, Overeem S, Oostendorp RA, Vlieland TP, Mulleners W, Hoogerwaard EM, Bloem BR, Munneke M (2010) The ParkinsonNet concept: Development, implementation and initial experience. Mov Disord 25, 823-829.

[8] Ypinga JHL, de Vries NM, Boonen LHHM, Koolman X, Munneke M, Zwinderman AH, Bloem BR (2017) Effectiveness and costs of specialised physiotherapy given via ParkinsonNet: A retrospective analysis of medical claims data. Lancet Neurol 17, 153-161.

[9] Berwick D, Nolan T, Whittington J (2008) The triple aim: Care, health and costs. Health Aff (Millwood) 27, 759-769.

[10] Goodwin N (2016) Understanding and evaluating the implementation of integrated care: A 'three pipe' problem. Int $J$ Integr Care 16, 19.
[11] Busetto L (2016) Great expectations: The Implementation of integrated care and its contribution to improved outcomes for people with chronic conditions. Int J Integr Care 16, 16.

[12] Minkman M (2017) Innovatie van organisatie en governance van integrale zorg, Tilburg University, Tilburg.

[13] Munneke M, Nijkrake MJ, Keus SH, Kwakkel G, Berendse HW, Roos RA, Borm GF, Adang EM, Overeem S, Bloem BR; ParkinsonNet Trial Study Group (2010) Efficacy of community-based physiotherapy networks for patients with Parkinson's disease: A cluster-randomised trial. Lancet Neurol 9, 46-54.

[14] Sturkenboom IH, Graff MJ, Hendriks JC, Veenhuizen Y, Munneke M, Bloem BR, Nijhuis-van der Sanden MW; OTiP study group (2014) Efficacy of occupational therapy for patients with Parkinson's disease: A randomised controlled trial. Lancet Neurol 13, 557-566.

[15] Neuwirth EB, Bellows J, Jackson AH, Price PM (2012) How Kaiser Permanente uses video ethnography of patients for quality improvement, such as in shaping better care transitions. Health Aff (Millwood) 31, 1244-1250. 